\title{
Effect of Plasticizer and Concentration on Characteristics of Bioplastic Based on Cellulose Acetate from Kapok (Ceiba pentandra) Fiber
}

\author{
Rahmatullah", Rizka Wulandari Putri ${ }^{1}$, Muhammad Rendana', Untung Waluyo', Tedi Andrianto ${ }^{1}$ \\ ${ }^{1}$ Chemical Engineering Department, Faculty of Engineering, University of Sriwijaya, Palembang 30862, Indonesia \\ *Corresponding author: rahmatullahoft.unsri.ac.id
}

\begin{abstract}
Synthetic plastics made from petroleum material have been widely used in all industrial sectors. They bring some environmental problems. Semi-synthetic plastics or biodegradable plastics which are made from natural polymers such as cellulose can solve this problem. Biodegradable plastics can fulfill the needs of society because they can be decomposed easily into the environment. Previous research of bioplastic production with kapok fiber as raw material only used glycerol as a plasticizer without the analysis of the characteristics of the bioplastic. In this study, variations of the plasticizer with sorbitol were carried out as well as physical and chemical analysis on the characterization of bioplastic products. This research used laboratory experimental methods through several processes: kapok fiber isolation, cellulose acetate production, purification, and manufacture of bioplastics. The characteristics of bioplastics were analyzed using some parameters such as density, tensile strength, elongation, Young's modulus, water absorption, biodegradability, compound group analysis using Fourier-Transform Infrared Spectrometer (FTIR), and bioplastic morphology analysis by using Scanning Electron Microscopy (SEM). This study aimed to determine the effect of plasticizer and concentration on the bioplastics characteristics that was divided into several different concentrations of glycerol and sorbitol plasticizers (20\%, 30\%, and $40 \%$ ). The fabrication of composite bioplastics used the cellulose acetate from kapok fiber, starch, and types of plasticizer (glycerol, and sorbitol). The results of the study showed that the addition of different plasticizers, such as glycerol and sorbitol gave distinct effects on the bioplastics product characteristics. The optimum concentration of glycerol addition affected the bioplastic characteristics with the best results were $40 \%$ concentration generate density of $0.836 \mathrm{~g} / \mathrm{mL}$, tensile strength of $0.818 \mathrm{MPa}$, water absorption value of $22.23 \%$, and degradation plastic mass about $39.7 \%$. The addition of sorbitol also affected the bioplastic characteristics, where the best results were $40 \%$ concentration produced bioplastic density of $0.941 \mathrm{~g} / \mathrm{mL}$, percent elongation at $3.94 \%$, young's modulus of $0.726 \mathrm{MPa}$, and degradation mass of $32.05 \%$. The morphology of bioplastic showed high homogeneity at concentrations of $40 \%$ glycerol and $30 \%$ sorbitol.
\end{abstract}

Keywords

Bioplastic, Gliserol, Kapok Fiber, Celulosae Asetate, Sorbitol

Received: 10 September 2021, Accepted: 12 December 2021

https://doi.org/10.26554/sti.2022.7.1.73-83

\section{INTRODUCTION}

Human activities depend on plastic materials in their entire life. They use plastics for packaging in shopping, household furniture, medical devices, and other daily needs. The plastics are thrown away at the garbage places and most of them are non-degradable materials which then cause environmental and human health problems.

In 2006, the Ministry of Environment and Forestry reported that Indonesia country contributes around 9.85 billion pieces of plastic bags every year, which are released from over 90 thousand modern retail outlets. Plastic wastes generally need from 20 to 500 years for the decomposition process (Ratnawati, 2020). It causes the garbage piles in Indonesia that leads to disruption of environmental sustainability. In addition, Jambeck et al. (2015) explained that Indonesia is one of the second-largest contributors to plastic waste in the world with 3.2 million tons of plastic waste. Around 12.7 million tons of plastic wastes have been dumped into the ocean by 192 coastal countries including Indonesia. These issues motivate many researchers to find out the solution to plastic waste problems through alternative plastics with environmentally friendly characteristic.

Bioplastic production is one of the solutions to reduce the problem of environmental pollution. These bioplastics can be developed by natural polymers like cellulose. Cellulose is one of the natural resources that potentially developed as a 
biopolymer due to its abundant presence, renewable sources, and easily decomposed. Several plants are based on cellulosic sources for making bioplastics such as corn cobs, banana peels, sweet potato peels, and other plants. One of the natural fibers that are potentially used as bioplastics raw material is kapok (Ceiba pentandra) fiber.

Kapok grows easily in Indonesia, especially in tropical areas, such as on Java island (Mardiyati et al., 2018). Indonesia is one of the largest cotton-producing countries in the world, accounting for 58,693 tons or $62.69 \%$ of the world's total production. The production of cottonwood plantations in East Java in 2015 achieved at 170 tons from manufactory farms, 1544 tons from the large private farms, and 25,288 tons for all regions in East Java (of East Java Province, 2018).

In previous studies, Haryono et al. (2019) converted kapok (C.Pentandra) seeds oil into biodiesel, while leaf extract of kapok (C.Pentandra) was used to treat internal heat (Febrila, 2019). Kapok (C.Pentandra) could also be used as activated charcoal for adsorbent (Wahyuni et al., 2017), a mixture of rice husk briquettes (Lestari, 2015), microcrystalline cellulose (Mardiyati et al., 2018), composite reinforcement (Purnawati et al., 2018), raw material for furfural production (Andaka, 2016), and paper fabrication (Kathomdani, 2018).

Several studies observed the use of cellulose as bioplastics raw material. Andahera et al. (2019) analyzed the effect of adding the type and concentration of plasticizers on the quality of cellulose-based bioplastics from oil palm empty fruit bunches. Pratiwi et al. (2016) produced cellulose from rice straw waste (Oryza sativa) as the raw material of bioplastics. Tamiogy et al. (2019) analyzed the cellulose production from betel nut peel waste as filler of bioplastics with glycerol variations. Rahmatullah et al. (2020) produced cellulose acetatebased bioplastics from kapok fiber by varied reaction time and glycerol concentration to determine the cellulose acetate yield and also bioplastics characteristics.

However, studies that have analyzed the biodegradable plastic of cellulose acetate based on kapok fiber were still very limited. Kapok fiber has the potential to be the raw material of cellulose acetate for bioplastic production due to the content of cellulose about 35\%-64\% (Chaiarrekij et al., 2012). This work was conducted to study the effect of the type and concentration of plasticizers on the characteristics of bioplastic. In this study, the characteristics of bioplastic products were tested in physical and chemical analysis. In general, the added plasticizers, sorbitol, and glycerol gave different effects on the bioplastic product, where the best results were obtained by adding sorbitol with a density value and degradation time that met the Indonesian Nasional Standard. It can be concluded that cellulose from kapok fiber has the potential to be used as a material in bioplastic production.

\section{EXPERIMENTAL SECTION}

\subsection{Materials and Methods}

This research is a modification of Andahera et al. (2019) and Rahmatullah et al. (2020) in previous works. The process of cellulose-based bioplastics production from kapok fibers consisted of four stages: the cellulose isolation process, cellulose acetate synthesis, cellulose acetate purification, and the bioplastic manufacturing process. The synthesis of bioplastics in this research used kapok fiber (original), starch (tapioca flour) (by PT Melati Putra Jaya), aqua dest (by Technical), alkaline water pH 8 (by local), Glycerol (by Merck), sorbitol (by Technical), sodium hydroxide ( $\mathrm{NaOH})$ (by Merck), glacial acetic acid $\left(\mathrm{CH}_{3} \mathrm{COOH}\right.$ (by Merck), acetic anhydride $\left(\left(\mathrm{CH}_{3} \mathrm{CO}\right)_{2} \mathrm{O}\right)$ (by Merck), sulfuric acid $\left(\mathrm{H}_{2} \mathrm{SO}_{4}\right)$ (by Merck). The characterization of bioplastics using FTIR analysis using Nicolet iS 10 FT-IR Spectrometer, the SEM analysis using SEM EDX Tescan Vega3.

\subsubsection{Kapok Fiber Cellulose Insulation}

Temperature of $100^{\circ} \mathrm{C}$ until constant weight. The dried kapok fiber was delignified with $12 \%$ sodium hydroxide $(\mathrm{NaOH})$ solution $(3.4 \mathrm{M})$ for 3 hours at a temperature of $75^{\circ} \mathrm{C}$. The delignified kapok fiber is filtered and washed with distilled water until the acidity was neutral then bleached with $3.5 \%$ sodium hypochlorite $(\mathrm{NaOCl})$ solution and mixed with aqua dest (1:1) at $75^{\circ} \mathrm{C}$ for 10 minutes. The bleached kapok fiber was washed thoroughly with distilled water until the acidity was neutral. Neutralized kapok fiber was dried in an oven at $100^{\circ} \mathrm{C}$ until a constant weight.

\subsubsection{Synthesis of Cellulose Acetate Kapok Fiber}

The process of synthesizing cellulose acetate from kapok fiber was carried out in several stages. Total 10 grams of kapok fiber cellulose was put into a three-neck flask, then added $50 \mathrm{~mL}$ of glacial acetic acid $\left(\mathrm{CH}_{3} \mathrm{COOH}\right)$, and $0.5 \mathrm{~mL}$ of sulfuric acid. Afterward, it was stirred evenly for 3 minutes, covered the flask with aluminum foil, and left for 1 hour. After 1 hour, $50 \mathrm{~mL}$ of anhydrous acetic acid $\left(\left(\mathrm{CH}_{3} \mathrm{CO}\right)_{2} \mathrm{O}\right)$ was added and followed by the addition of $20 \mathrm{~mL}$ of glacial acetic acid. Then it was heated for 30 minutes at a temperature of $50^{\circ} \mathrm{C}$. The mixture was cooled down at room temperature. Added 50 $\mathrm{mL}$ of $70 \%$ glacial acetic acid $(7.1 \mathrm{M})$ and $0.14 \mathrm{~mL}$ (3 drops) of sulfuric acid then reacted for 3 hours at $50^{\circ} \mathrm{C}$. After the reaction was complete, the mixture was allowed to cool down until the temperature was lowered and then proceed with the purification process.

\subsubsection{Purification of Cellulose Acetate}

The synthesized cellulose acetate solution was put into a 1000 $\mathrm{mL}$ beaker, slowly added $25 \mathrm{~mL}$ of distilled water while kept stirring. Total $500 \mathrm{~mL}$ of distilled water was added and stirred until homogenous state. The cellulose acetate solution was left until it became a solid phase mixed with a solvent. The cellulose acetate solution was filtered using a Buchner vacuum funnel with distilled water in addition to obtaining cellulose acetate solids. Then, the cellulose acetate solid was washed and filtered using a Buchner vacuum funnel repeatedly until neutral. Neutralized cellulose acetate was dried in an oven at a temperature of $100^{\circ} \mathrm{C}$ to a constant weight and pulverized. 


\subsubsection{Bioplastic Manufacturing}

Total 1.5 grams of starch was dissolved in $9 \mathrm{~mL}$ of distilled water and heated for 15 minutes at $70^{\circ} \mathrm{C}$ while stirring continuously until gelatin was formed. Then 1 gram of cellulose acetate was added and plasticizer, glycerol, and sorbitol were added in different concentrations such as $20 \%, 30 \%$, and $40 \%$, respectively. The solution was stirred and heated at $50^{\circ} \mathrm{C}$ for 15 minutes until it appeared thick and clear. The produced bioplastic solution was molded in a petri dish lined with aluminum foil and left at room temperature to dry and form a bioplastic sheet.

\subsection{Bioplastic Characteristic Analysis}

\subsubsection{Analysis of Bioplastic Functional Groups}

The kapok fiber cellulose was analyzed by FTIR (Fourier Transform InfraRed) machine. The sample was placed into the set holder, then searched for the appropriate spectrum. The result would be obtained a diffractogram of the relationship between wavenumber and transmittance. The FTIR spectra were recorded using a spectrophotometer at room temperature.

\subsubsection{Bioplastic Film Surface Test}

The bioplastic film test observed the surface of the bioplastic film by using the SEM (Scanning Electron Microscopy) machine. The SEM analysis was operated by following a procedure as the specimen was fixed in size about $12.5 \mathrm{~mm}$ then inserted into the chamber. The pumping procedure was started by clicking on the PUMP button in the vacuum panel then selecting the appropriate detector (SE or BSE). The accelerating voltage was set in $(5 \mathrm{kV}, 10 \mathrm{kV}, 20 \mathrm{kV}, 30 \mathrm{kV})$ using the combo box in the electron beam panel. By clicking on the HV button in the electron beam panel turns the high voltage on, it was started the heating of the tungsten filament It was continued by pressing right-click in the SEM Scanning window to open the menu and selected the minimum magnification function. The resolution mode (wide field and resolution) was chosen and selected beam intensity (BI 10 recommended).

\subsubsection{Bioplastic Density Test}

The density test was conducted based on the procedure carried out by Darni et al. (2017). A total $10 \mathrm{~mL}$ measuring cup was filled with $5 \mathrm{~mL}$ of water and the bioplastic sample was put into the measuring cup for 15 minutes. Then the new volume of water (v) was recorded and the actual volume of bioplastic was calculated by dividing the final volume of water by the initial volume of water. The density $(\rho)$ of bioplastic was obtained with the Equation 1 below:

$$
\rho=\frac{\mathrm{m}}{\mathrm{v}}
$$

Where $\rho$ was density (gram/mL), m was mass (gram) and $\mathrm{v}$ was volume $(\mathrm{mL})$

\subsubsection{Bioplastic Tensile Strength Test}

The process of testing the tensile strength of cellulose acetatebased bioplastics from the kapok fibers was carried out using the Universal Testing Machine. Samples were cut to a size of $2 \mathrm{~cm} \times 12 \mathrm{~cm}$. The sample was attached to a tensile tester with 1 fixed handle and 1 movable handle. Furthermore, the thickness and initial length of the sample were recorded until the broken sample. The maximum force that splitted sample was figured on the display device. The cross-sectional area is obtained by multiplying the length with the initial thickness of the sample. The tensile strength was calculated using the formula:

$$
\sigma=\frac{\mathrm{F}}{\mathrm{A}}
$$

Where $\sigma$ was tensile strength (MPa), F was force acting $(\mathrm{N})$, A was a cross-sectional area $\left(\mathrm{mm}^{2}\right)$

\subsubsection{Percent Elongation of Bioplastic}

The elongation analysis of cellulose acetate-based bioplastic from kapok fiber produced was carried out by using the Universal Testing Machine. Based on the procedure from Rifaldi et al. (2017), the percent elongation of bioplastics produced could be calculated by Equation 3:

$$
\text { Elongation }(\%)=\frac{\mathrm{L}_{1}-\mathrm{L}_{0}}{\mathrm{~L}_{0}} \times 100 \%
$$

Where $\mathrm{L}_{1}$ was the final length of the test object, $\mathrm{L}_{0}$ was the initial length of the test object.

\subsubsection{Bioplastic Young's Modulus Test}

The Young's modulus value was obtained from the tensile strength and the percent elongation values that were generated by Equation 4 (Rifaldi et al., 2017):

$$
\mathrm{E}=\frac{\sigma}{\varepsilon / 100}
$$

Where $\mathrm{E}$ was Modulus Young (KPa), $\sigma$ was tensile strength $(\mathrm{KPa})$ and $\varepsilon$ was elongation percentage $(\%)$

\subsubsection{Water Resistance Test}

The initial bioplastic sample was weighed and the put into a container containing aquadest. The sample was taken out from the container every 10 seconds and weighed repeatly until obtained a constant final sample weight. The water absorbed on the bioplastic sample could be calculated by the following Equation 5 (Tamiogy et al., 2019).

$$
\operatorname{Water}(\%)=\frac{\mathrm{W}-\mathrm{W}_{o}}{\mathrm{~W}_{o}} \times 100 \%
$$

Where $\mathrm{W}_{o}$ was the initial sample weight $(\mathrm{g})$ and $\mathrm{W}$ was final sample weight $(\mathrm{g})$ 


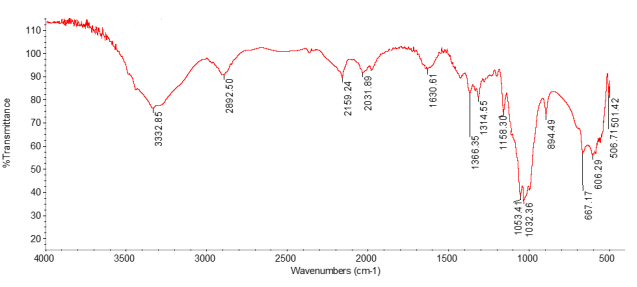

Figure 1. FTIR Spectrum of Kapok Fiber Cellulose

\subsubsection{Bioplastic Degradation Test}

The degradation process of cellulose acetate from kapok fiber used the loose soil as decomposer media with an acidity degree around $\mathrm{pH}$ 6-7. The degradation test was carried out with two variations. The first was conducted by stockpiling in soil for 4 days. The second, it placed bioplastics on the free air as long as they were completely degraded. The bioplastic samples were weighed before the degradation test and reweighed every day until up to 4 days. Degradation value was obtained from the percentage of mass degradation of bioplastic which was calculated based on Equation 6 below:

$$
\text { Biodegradation }(\%)=\frac{\mathrm{a}_{1}-\mathrm{a}_{2}}{\mathrm{a}_{1}} \times 100 \%
$$

Where $a_{1}$ was mass before testing (gram), a 2 was mass after testing (gram).

\section{RESULTS AND DISCUSSION}

\section{Characteristic Results of Kapok Fiber Cellulose}

The kapok fiber raw material that was processed through delignification and bleaching processes obtained a yield of about $47.5 \%$ bleached cellulose. The kapok fiber cellulose was analyzed by using FTIR to identify the functional groups. The results of the FTIR were shown in Figure 1.

The results of functional group analysis showed the absorption peak of the $\mathrm{O}-\mathrm{H}$ group at a wavenumber of $3332.85 \mathrm{~cm}^{-1}$. This result indicated that the bleached kapok fiber contained cellulose. This was supported by Rohmawati et al. (2018) which found after the isolation process in the $3349.78 \mathrm{~cm}^{-1}$ area, the cellulose content increased clearly. The isolated kapok fiber cellulose was indicated by the presence of certain cellulose groups, besides, the hydroxyl group, such as the methylene group of the C-H functional group at the absorption wave of 2892.50 $\mathrm{cm}^{-1}$ (Pavia et al., 2001). The kapok fiber cellulose result still contained lignin which was indicated by the $-\mathrm{OH}$ group at the wave number $1630.61 \mathrm{~cm}^{-1}$. This result was supported by Kumar et al. (2014) which found that the indication of lignin in cellulose product was shown by the presence of -OH groups at wavenumbers $1600-1700 \mathrm{~cm}^{-1}$. In addition, $\mathrm{C}=\mathrm{C}$ groups were observed at wave absorption $2031.89 \mathrm{~cm}^{-1}$ to 2159.24 $\mathrm{cm}^{-1}$.

3.1 Characteristics Results of Kapok Fiber Cellulose Acetate Cellulose acetate was produced by synthesizing kapok fiber cellulose with glacial acetic acid and anhydrous acetic acid with

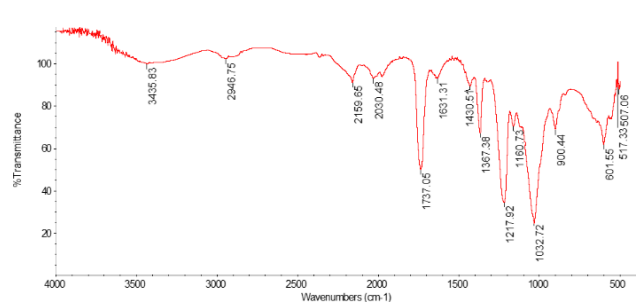

Figure 2. Cellulose Acetate FTIR Spectrum of Kapok Fiber

a sulfuric acid catalyst. The cellulose acetate in the form of a white solid was separated from water into a fine powder of cellulose acetate. The yield of cellulose acetate obtained 114.6 g. Cellulose acetate powder was identified to determine the characteristics of functional groups using the FTIR. Cellulose acetate FTIR test results could be seen in Figure 2.

The results of the FTIR functional group analysis showed the presence of a $\mathrm{C}=\mathrm{O}$ carbonyl group at a wavenumber of $1737.05 \mathrm{~cm}^{-1}$ and a $\mathrm{C}-\mathrm{O}$ ester group from an acetyl group at a wavenumber of 1160.73 and $1217.92 \mathrm{~cm}^{-1}$ (Figure 2 . This phenomenon indicated the formation of cellulose acetate compounds with a sharp peak at wave number $1737.05 \mathrm{~cm}^{-1}$ and the decrease in the intensity of the $\mathrm{OH}$ group could be caused by the substitution of the acetyl group. Nurhayati and Kusumawati (2014) explained the cellulose acetate compound was formed with a sharp peak at a wavenumber of $1755 \mathrm{~cm}^{-1}$ and the $\mathrm{OH}$ intensity decreased due to the substitution of the acetyl group.

The hydroxyl group in cellulose was sharper than the hydroxyl group in cellulose acetate, which was represented at wave $3435.85 \mathrm{~cm}^{-1}$. The FTIR spectrum of cellulose acetate showed the acetylation process did not deteriorate the main structure of cellulose, indicating the presence of a specific cellulose C-H group at $2946.75 \mathrm{~cm}^{-1}$, -O- group $1367.38 \mathrm{~cm}^{-1}$. This result was similar to a study by Rohmawati et al. (2018) that found the main structure of cellulose did not decay the acetylation process due to the presence of cellulose groups.

\subsection{Bioplastic Yield}

Bioplastics produced with cellulose acetate base from kapok fibers by the addition of starch as an adhesive additive (1:1.5). Bioplastic molding was carried out by glycerol and sorbitol addition as plasticizers with concentrations of $20 \%, 30 \%$, and $40 \%$ respectively. The mass yield from the manufacture of this bioplastic was presented in Table 1.

\subsection{The Effect of Type and Concentration of Plasticizer on Bioplastic Functional Groups}

The bioplastic characteristic test using FTIR aimed to identify the functional groups content of bioplastics based on the effect of the type and concentration of plasticizers.

Figure 3 showed the spectrum of cellulose acetate-based bioplastic from kapok fiber with different characteristics according to the concentration of glycerol indicated the presence of $\mathrm{O}-\mathrm{H}$ groups. The wavenumber of $20 \%$ glycerol concentration 
Table 1. Bioplastics Yield

\begin{tabular}{cc}
\hline Plasticizer Concentration & Bioplastic Mass (gram) \\
\hline Glycerol 20\% & 2.77 \\
Glycerol 30\% & 2.9 \\
Glycerol 40\% & 3.15 \\
Sorbitol 20\% & 2.71 \\
Sorbitol 30\% & 2.96 \\
Sorbitol 40\% & 2.78 \\
\hline
\end{tabular}

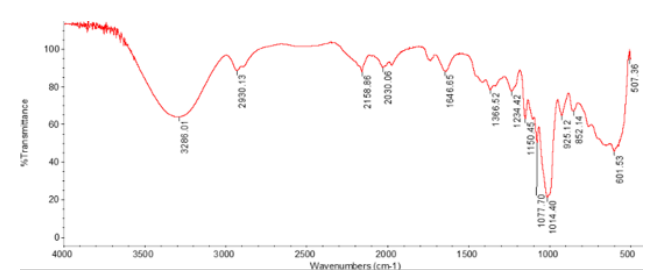

(a)

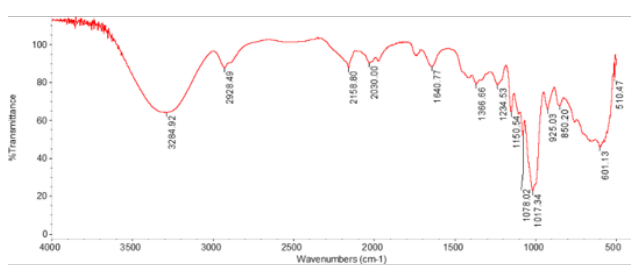

(b)

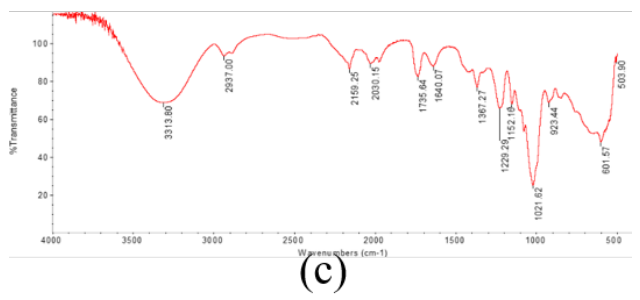

Figure 3. FTIR Result of Bioplastic with added plasticizer: a) 20\% Glycerol; b) 30\% Glycerol; and c) 40\% Glycerol

bioplastic was $3286.01 \mathrm{~cm}^{-1}$. Bioplastic with $30 \%$ glycerol concentration was the sharpest wavenumber with an absorption area of $3284.92 \mathrm{~cm}^{-1}$. The highest wavenumber in bioplastics with the addition of $40 \%$ glycerol concentration was 3313.80 $\mathrm{cm}^{-1}$. This hydroxyl group indicated the presence of polymer compounds (Lopes et al., 2018). The different concentrations of glycerol plasticizer lead to the different transmittance spectrum due to the addition of glycerol which resulted from hydrogen bonds formation (Jannah, 2017).

The wavenumber peaks at each concentration of glycerol $20 \%, 30 \%$, and $40 \%$ were $2930.13 ; 2928.49$; and $2937 \mathrm{~cm}^{-1}$, respectively. These results indicated the presence of $\mathrm{C}-\mathrm{H}$ groups of cellulose acetate. Based on the result of Pavia et al. (2001), the C-H functional group was a cellulose acetate framework that appeared at wavenumber of $2800-3000 \mathrm{~cm}^{-1}$. The wavenumber of each glycerol concentration of $20 \%, 30 \%$, and

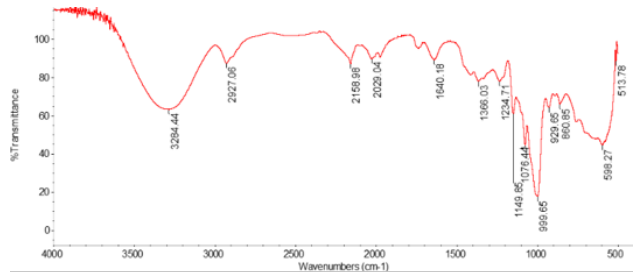

(a)

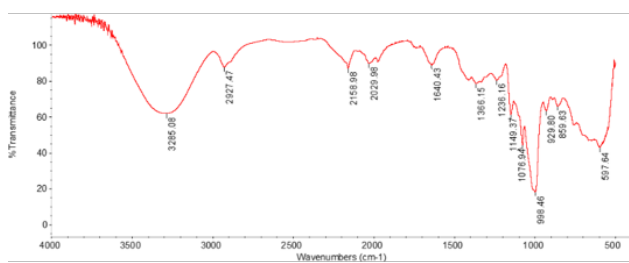

(b)

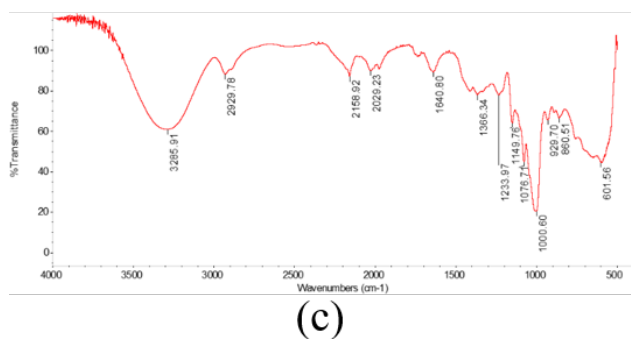

Figure 4. FTIR Result of Bioplastic with added plasticizer: a) $20 \%$ Sorbitol; b) $30 \%$ Sorbitol; and c) $40 \%$ Sorbitol

$40 \%$ were $1646.65,1640.77$, and $1640.07 \mathrm{~cm}^{-1}$, respectively, which indicated the presence of $\mathrm{C}-\mathrm{C}$ groups of starch. The typical spectrum of starch appeared at a wavenumber of 1649 $\mathrm{cm}^{-1}$ which indicated the presence of C-C bonds (Salinas-Jasso et al., 2021).

FTIR analysis was conducted to identify the functional groups and to compare the characteristics differences by using a sorbitol plasticizer. Figure 4 showed the FTIR test results for bioplastics with the addition of the plasticizer sorbitol.

Figure 4 showed the wave number peaks of cellulose acetatebased bioplastics from kapok fiber. The peak wavenumbers were $3284.44 \mathrm{~cm}^{-1}, 3285.08 \mathrm{~cm}^{-1}, 3285.91 \mathrm{~cm}^{-1}$ indicated the presence of hydroxyl $(\mathrm{O}-\mathrm{H})$ groups and the presence of hydrocarbons $(\mathrm{C}=\mathrm{H})$ at wavenumbers $2927.08 \mathrm{~cm}^{-1}, 2927.47$ $\mathrm{cm}^{-1}$, and $2929.78 \mathrm{~cm}^{-1}$, indicating the compound of cellulose acetate. The hydroxyl group also exhibited the presence of sorbitol compounds. This was related to the result of Kinney et al. (2012) which found that sorbitol had an absorption peak at a wavenumber of $3373 \mathrm{~cm}^{-1}$. The wavenumber at $1640 \mathrm{~cm}^{-1}$ indicated the presence of $\mathrm{C}-\mathrm{C}$ groups of starch in bioplastics.

FTIR analysis results in Table 2 represented that the synthesized bioplastics had similar wavelength values to their constituent raw materials. The addition of glycerol and sorbitol to cellulose acetate from kapok fiber did not denote the formation of new functional groups, however, the physical functional 
Table 2. Results of FTIR Analysis on The Main Groups of Bioplastic Samples and The Comparison on Their Constituent Components

\begin{tabular}{cccccc}
\hline \multirow{2}{*}{ Component } & -OH Stretch & C-H Strecth & C-H Bending & C-O Acetyl & C-O Stretch \\
\hline Cellulose acetate* & $3200-3600$ & $2850-3000$ & $1350-1480$ & $1210-1320$ & $1000-1300$ \\
Starch** & 3388 & 2929 & & & \\
Gliserol** $^{\text {Sorbitol** }}$ & $3286-3379.29$ & $2880-2935$ & $1200-1300$ & & $1000-1100$ \\
G40 & 3257 & 2937 & & & \\
G30 & 3313.8 & 2937 & 1367.27 & 1229.29 & 1021.62 \\
G20 & 3284.92 & 2928.49 & 1366.66 & 1234.53 & 1017.34 \\
S40 & 3286.01 & 2930.13 & 1366.52 & 1234.42 & 1014.4 \\
S30 & 3285.91 & 2929.78 & 1366.34 & 1233.97 & 1000.6 \\
S20 & 3285.08 & 2927.47 & 1366.15 & 1236.16 & \\
\hline
\end{tabular}

Table 3. Comparison of Characterization of The Bioplastic

\begin{tabular}{cccccccc}
\hline \multirow{2}{*}{ Parameter } & Indonesian National & \multicolumn{6}{c}{ Bioplastic from kapok fiber with variation of type and concentration plasticizer } \\
& Standard & G20\% & G30\% & G40\% & S20\% & S30\% & S40\% \\
\hline Density (g/mL) & $0.941-0.955$ & 0.602 & 0.753 & 0.836 & 0.753 & 0.836 & 0,941 \\
Tensile strength (MPa) & $24.7-302$ & 0.164 & 0.014 & 0.818 & 0.327 & 0.204 & 0.286 \\
Elongation (\%) & $21-220$ & 2.63 & 1.29 & 2.59 & 2.63 & 1.35 & 3.94 \\
Modulus Young (MPa) & $117-137$ & 0.622 & 0.111 & 0.316 & 0.124 & 0.151 & 0.726 \\
Water absorption (\%) & 21.5 & 37.72 & 27.61 & 22.23 & 37.27 & 50.39 & 51.17 \\
Mass of degradation & $>60 \%$ & 26.11 & 28.46 & 39.7 & 23.78 & 23.36 & 32.05 \\
& $(7$ days) & (4 days) & $(4$ days) & $(4$ days) & $(4$ days) & $(4$ days) & $(4$ days) \\
Biodegradation time & 60 days & 27 days & 27 days & 27 days & 27 days & 27 days & 27 days \\
\hline
\end{tabular}

group interactions were shifted in wavenumbers in the $\mathrm{OH}$, $\mathrm{CH}$, and $\mathrm{CO}$ groups through the spectrum readings. The $\mathrm{OH}$ and $\mathrm{CO}$ stretch groups indicated the hydrophilic groups due to water molecules could cause microorganisms in the environment to enter the bioplastic matrix and lead the bioplastic damage (Nahir, 2017). The presence of the C-O functional group indicated that the plastic film could be degraded well in the soil and was easy to decompose (Siregar, 2009). These phenomenons signified that the process of bioplastic production was a mixing process without any reaction of its constituent materials, this phenomenon caused the bioplastic products to have properties that seem like their constituent components and were easy to decompose.

\subsection{The effect of Type and Concentration of Plasticizer on Bioplastic Surface Morphology}

SEM analysis on cellulose acetate-based bioplastic from kapok fiber aimed to determine the surface characteristics of the bioplastic film and morphological structure of bioplastic. Bioplastic surface analysis was carried out by the SEM analysis with $2,000 \times$ magnification. Figure 5 represented SEM results bioplastics with the addition of glycerol in different concentrations.

Figure 5 showed that the bioplastic with the addition of $20 \%$ glycerol obtained an irregular and rift surface. There was open pores appearance with cracks and holes. The cracks

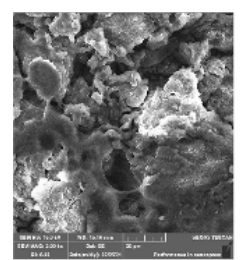

(a)

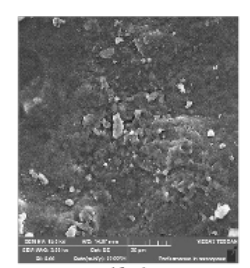

(b)

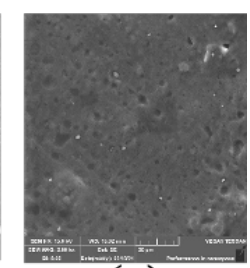

(c)
Figure 5. SEM Test Results of Bioplastic Plasticizer Glycerol Concentration a) $20 \%$, b) $30 \%$, and c) $40 \%$

might be caused by the cellulose acetate that was incompletely dissolved with starch in the addition of $20 \%$ glycerol solvent. The presence of cavities and cracks in bioplastics indicated the cellulose acetate with glycerol as a plasticizer did not bind to each other due to the small glycerol concentration (Tamiogy et al., 2019). The surface of bioplastics with the addition of $30 \%$ glycerol seem smoother than the addition of $20 \%$ glycerol, but it still had visible lumps of particles on the surface. However, there were no visible pores or cracks on the surface of the bioplastic $30 \%$ glycerol. It might be caused by the mixing process of starch, cellulose acetate, and glycerol solvent have been well homogenized. This was supported by the result of 


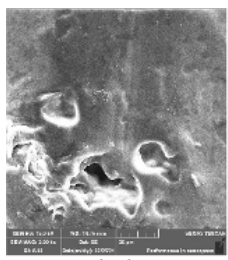

(a)

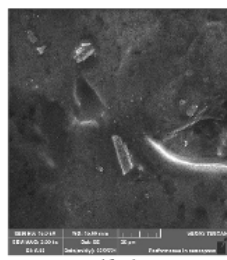

(b)

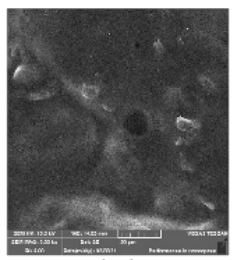

(c)
Figure 6. SEM Test Results of Bioplastic Plasticizer Sorbitol Concentrations a) $20 \%$, b) $30 \%$, and c) $40 \%$

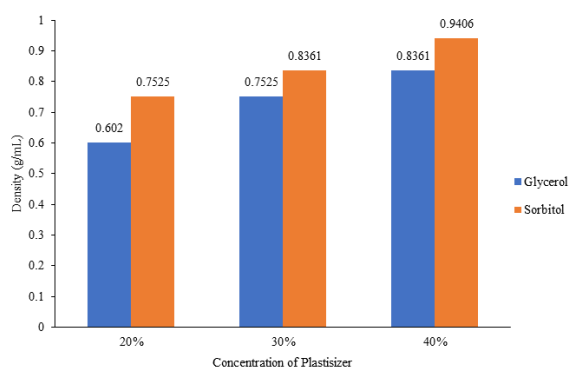

Figure 7. Results of Bioplastic Density on The Type and Plasticizer Concentration Variation

Maneking et al. (2020) that stated the combination of starch, glycerol, water, and acetic acid combination showed the smooth surface morphology without cracks and pores were formed. The addition of $40 \%$ glycerol bioplastic surface was slightly smoother than the addition of $20 \%$ and $30 \%$ glycerol. However, there were still found few visible pores, cracks, and bumps on the surface of the bioplastic. The results of the SEM analysis of bioplastics with sorbitol plasticizer were shown in Figure 6 .

Figure 6 showed the results of SEM analysis from the bioplastic with the addition of $20 \%$ sorbitol. The result found the surface of the bioplastic was quite smooth and raggy. It was also had some pores and cracks on the surface of the bioplastic sample. The bioplastic surface with $30 \%$ sorbitol had some pores and cracks but less than $20 \%$ sorbitol. On the other hand, the addition of $40 \%$ sorbitol on bioplastic had a slightly smoother surface with fewer pores than $20 \%$ and $30 \%$ sorbitol. The tight surface of the bioplastic lead to higher resistance of water absorption (Setiawan et al., 2015).

\subsection{The Effect of Type and Concentration of Plasticizer on Bioplastic Density}

Density analysis aimed to determine the density of the atoms compounds in bioplastic material that interacted with each other. The interaction affected the mechanical properties of the material. The denser the bioplastic, the higher its mechanical properties. The relationship between the type and concentration of plasticizer on the bioplastic density was shown in Figure 7.

The results showed that the increased density was influ-

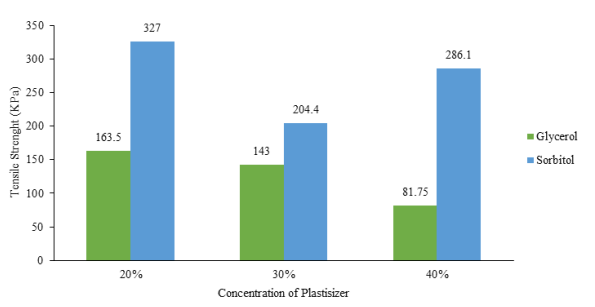

Figure 8. Results of Bioplastic Tensile Strength Based on the Type and Plasticizer Concentration Variation

enced by the high concentration of plasticizer added according to each type of plasticizer glycerol and sorbitol. The lowest density was obtained from the glycerol plasticizer with a concentration of $20 \%(0.602 \mathrm{~g} / \mathrm{mL})$. While the highest density value was found in $40 \%$ glycerol $(0.836 \mathrm{~g} / \mathrm{mL})$. Similarly, the concentration of $40 \%$ sorbitol lead to the highest density value. The type and concentration of plasticizers had a significant effect on the density value of the bioplastic products. This was supported by Darni et al. (2017) who stated that the higher the density value of a material would lead to the tighter the molecular structure. The bioplastic product had a tight structure, thus it would be more difficult for water molecules to enter the bioplastic pores. The density value of cellulose acetate-based bioplastic from kapok fiber with a $40 \%$ concentration of sorbitol plasticizer was $0.941 \mathrm{~g} / \mathrm{mL}$, which was closest to the density of LDPE plastic. The density value of LDPE ranged from 0.941 to $0.955 \mathrm{~g} / \mathrm{mL}$ (Darni et al., 2017). Most of the bioplastic density values produced were still low and far from to the density values of LDPE. This was due to the mixing of cellulose acetate, starch, and plasticizers in the manufacture of bioplastics were not homogeneous. Based on the result of Tamiogy et al. (2019), the fluctuating density value of the bioplastic film occurred due to the inhomogeneous mixing between starch and cellulose.

\subsection{The Effect of Type and Concentration of Plasticizer on Tensile Strength of Bioplastics}

Tensile strength analysis was carried out to determine the effect of the type and concentration of plasticizer on the tensile strength of cellulose acetate-based bioplastic from kapok fiber that was shown in Figure 8. Tensile strength analysis aimed to determine the ability of bioplastics to restrain the weight of the given load until it broke (Andahera et al., 2019).

The tensile strength values of bioplastics product from each type and concentration of plasticizers variant ranged from 81.75 to $327 \mathrm{KPa}$. The highest bioplastic tensile strength value was obtained at a $20 \%$ concentration of sorbitol plasticizer, which was able to hold a load of $327 \mathrm{KPa}$. This was consistent with another study by Azizaturrohmah (2019) where the maximum tensile strength was obtained at the concentration of $20 \%$ sorbitol.

The bioplastics with $40 \%$ glycerol concentration had the 


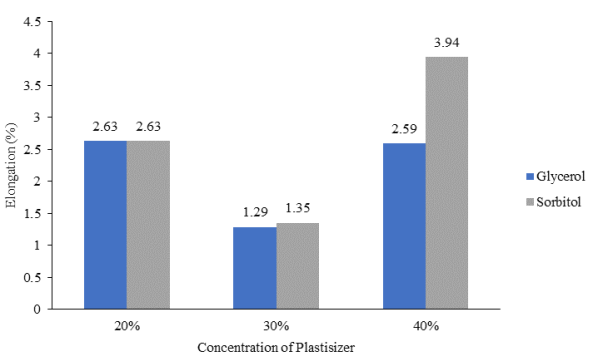

Figure 9. The Percent Elongation of Bioplastics on variation of Type and Plasticizer Concentration

lowest tensile strength value with the capability to hold a load of $81.75 \mathrm{KPa}$. The bioplastic tensile strength of the glycerol plasticizer decreased as the concentration was added. Based on the result by Intan and Wan (2011), the higher the concentration of plasticizer leads to the decrease in interaction between bioplastic molecules. It involved the bonds between bioplastic molecules became weak which lead to lower the tensile strength value.

The addition of sorbitol as a bioplastic plasticizer resulted in a higher tensile strength value than glycerol plasticizer. Riza et al. (2013) also showed a similar result that sago starch bioplastic with sorbitol plasticizer had a higher tensile strength value than glycerol plasticizer. This phenomenon was because glycerol had a smaller molecular weight than sorbitol. Glycerol was easier to enter into the polysaccharide bonding spaces, as the increase of number of spaces in bonds and the decrease of intermolecular bonds (Ningsih, 2015). According to Sitompul and Zubaidah (2017), the molecular structure of sorbitol was difficult to insert into polysaccharide bonds because the molecules of sorbitol were larger than glycerol thus it could stretch the existing bonds. Besides, sorbitol had the ability to produce bioplastics with greater tensile strength than glycerol because of sorbitol crystallinity (Unsa and Paramastri, 2018).

\subsection{The Effect of Plasticizer Type and Concentration on Bioplastic Elongation Percentage}

The elongation percentages analysis of cellulose acetate-based bioplastic from kapok fiber aimed to determine the percentage of the bioplastic length changes before it was broken off. Figure 9 presented the effect of the type and concentration of plasticizer on the percent elongation value.

The elongation percentage of the bioplastic products was quite different for each type and concentration of plasticizer. The differences were due to the distinct compositions of the bioplastics product. The elongation value ranged from 1.29 to $3.94 \%$. The addition of $20 \%$ plasticizer to glycerol and sorbitol showed the same result as the elongation value of about $2.63 \%$. The elongation percentages value decreased at the concentration of $30 \%$ plasticizer. The highest percentage of elongation was obtained from the addition of $40 \%$ sorbitol about $3.94 \%$. The addition of $30 \%$ glycerol obtained the smallest elongation

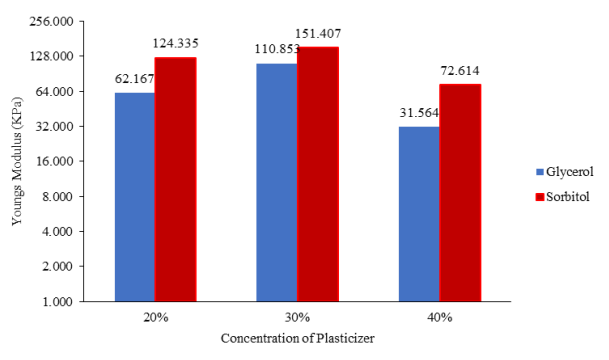

Figure 10. Young Modulus Young of Bioplastic base on type and Plasticizer concentration

percentage of about $1.29 \%$.

The elongation value of bioplastic with the addition of the plasticizer concentration of $40 \%$ increased significantly. This increase occurred because the plasticizer would reduce the intermolecular bonds between amylose and amylopectin with starch or cellulose acetate thus it affected the hydrogen bonding of starch molecules with the plasticizer (Sanyang et al., 2015). da Rosa Zavareze et al. (2012) revealed that the elongation percentage of polymeric materials depended on the mobility of the molecular chains of a polymer.

\subsection{The Effect of Plasticizer Type and Concentration on Young's Modulus of Bioplastics}

Young's modulus test on cellulose acetate-based bioplastic from kapok fiber aimed to determine the elasticity value of the resulting bioplastic. Young's modulus value was calculated by comparing the tensile strength (tensile strength) to the elongation at a breakpoint (Rifaldi et al., 2017). Figure 10 showed the results of Young's modulus of bioplastic according to the type and concentration of plasticizers.

Based on Figure 10, the highest value of Young's modulus was obtained in a $30 \%$ concentration of sorbitol plasticizer about $151.41 \mathrm{KPa}$. While the lowest value of Young's modulus was $31.5637 \mathrm{KPa}$ in a $40 \%$ glycerol plasticizer. The decrease in the value of Young's modulus was caused by the amount of concentration of plasticizer. The increase of plasticizer concentration leads to the increase of bioplastic elasticity. In contrast, it caused a smaller of Young's modulus value. According to Nahwi (2016), glycerol plasticizer was more effective because of its ability to reduce internal hydrogen bonds by increasing the empty space between molecules. Also, it could be affected by the reduction of stiffness and the increase of the bioplastics flexibility. The empty space would be filled by a plasticizer that reduced the interaction tension between starch molecules.

\subsection{The Effect of Type and Concentration of Plasticizer on Bioplastic Water Resistance}

Water-resistance test aimed to determine the ability of bioplastics to absorb water. The water absorption capacity of bioplastics was expected to be low to prevent bioplastics defects. Figure 11 represented the bioplastic water adsorption percentage according to the type and concentration of the plasticizer. 


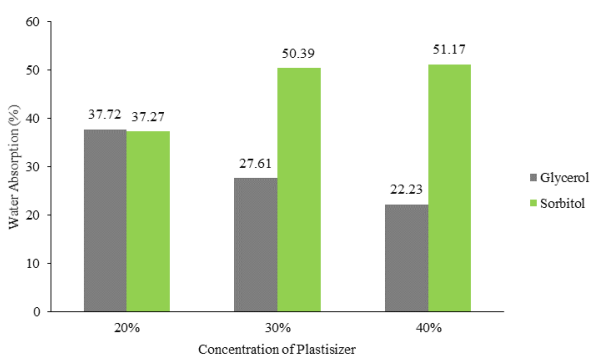

Figure 11. The Water Absorption Results on the Type and Concentration of Plasticizer variation

Figure 11 showed that the higher concentration of glycerol resulted in lower water absorption. This indicated that the higher concentration of glycerol added, the water would be more difficult to be absorbed and the bioplastic was more resistant to the water. Contrarily, the increase of sorbitol concentration would lead to the higher absorption of water.

The water absorption value of bioplastic with the addition of sorbitol was significantly above the average water absorption in glycerol bioplastics. The higher absorption capacity affected the lower water resistance product. The best water resistance characteristics were obtained in the bioplastics with the concentration of $40 \%$ glycerol about $22.23 \%$ of water absorbed and $37.37 \%$ of water absorption in $20 \%$ sorbitol.

The results of this study were different from previous studies. A study by Tamiogy et al. (2019) found that the water absorption of bioplastic was fluctuating at each concentration of plasticizer. The type and concentration of plasticizers could affect the value of the water-resistance of bioplastic where the addition of plasticizers could increase the permeability of the bioplastic product.

The low water absorption and the high glycerol concentration were influenced by the small glycerol molecule size thus it easily entered the intermolecular bonds. The distance between molecules was wider thus the cellulose acetate and starch could easily enter to fill the distance between molecules. This phenomenon affected the water became difficult to enter the molecule (Azizaturrohmah, 2019). In contrast, the high absorption value occurred in the increase in sorbitol concentration due to the larger sorbitol molecule size. The distance between molecules became closer thus the cellulose acetate and starch was difficult to fill the bond distance. The water would be easily absorbed in a bond distance of bioplastics (Maghfur, 2015). The bioplastic product was more resistant to water in the addition of glycerol as a plasticizer. It had a good absorption value compared with bioplastics with sorbitol plasticizer.

\subsection{The Effect of Plasticizer Type and Concentration on Bioplastic Biodegradation}

The biodegradation analysis of cellulose acetate-based bioplastic from kapok fiber aimed to determine the decomposition time for bioplastics when it was disposed to the environment.

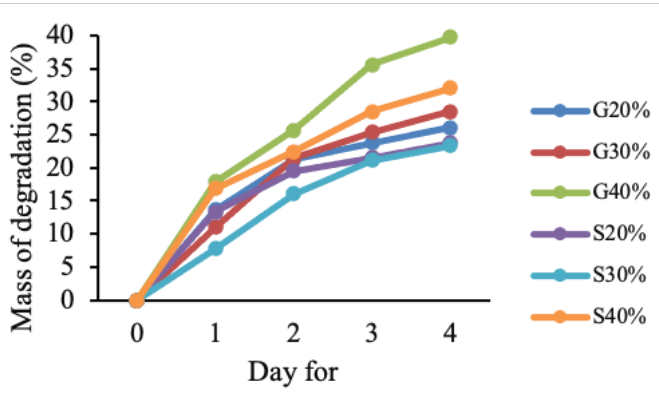

Figure 12. Results of Degraded Bioplastic Mass Percentage Based on The Type and Concentration of Plasticizer

The process of biodegradation analysis was carried out by burying with soil then observing the bioplastic mass degradation percentage from the first day to the fourth day. The results of the mass percent of the degraded bioplastics were presented in Figure 12.

The percentage yield of degraded bioplastic mass increased from the first day to the fourth day with a significant increase in high concentrations of plasticizer. The addition of $40 \%$ glycerol concentration leads to the highest degradation mass percentage about $39.7 \%$. While there was a fluctuating degradation mass percentage in the addition of sorbitol. The highest percentage of degradation $40 \%$ sorbitol was $32.36 \%$ of the mass degraded. The mass percent yield of degraded bioplastic was different from a study by Andahera et al. (2019) where the largest percentage of degraded mass was obtained with the addition of sorbitol with the smallest concentration around $10 \%$. While the addition of $30 \%$ sorbitol had the smallest reduction value of the degraded mass. This difference was due to the homogeneity factor in the mixing of sorbitol with cellulose acetate and starch, where the mixing was not homogeneous, the bioplastic would be easily degraded by the soil.

The bioplastics biodegradation by buried with soil aimed to determine the time depth for bioplastics completely decomposing in soil. This biodegradation process was checked periodically every day to determine the development physical appearance changes of bioplastics decomposed for seven days. Bioplastic on the first day was the original form of bioplastic which was still intact and has not been degraded yet by the soil. On the $7^{\text {th }}$ day, the bioplastic have changed its form to become duller and began to be degraded by the soil, and there were some cracks on the bioplastics. Another study done by Isnaini (2019) showed that in the first week, Nipa fruticans' bioplastics were in the form of clear sheets. In the $2^{\text {nd }}$ week, the bioplastic changed color to a dull yellow and has decreased in mass. In the $3^{r d}$ week there was a decrease in mass and black spots appeared, while at the $4^{\text {th }}$ week there were more black spots on bioplastics. The degradation test with the addition of sorbitol reached the range of $22 \%$ - $70 \%$ in 1 week.

Bioplastics with the addition of glycerol plasticizer were easier to decompose than bioplastics with sorbitol plasticizer due 
to the characteristics of glycerol which was more easily bound to water than sorbitol. It affected bioplastics to be more easily damaged when they were placed in the soil. Moreover, the hydroxyl group $(\mathrm{O}-\mathrm{H})$ in glycerol would cause a hydrolysis reaction in bioplastics with water content in the soil that resulted in bioplastics damage (Ardiansyah, 2011). Meanwhile, bioplastics with sorbitol plasticizer had a longer degradation time due to the larger molecular weight of sorbitol that made stronger intermolecular bonds. The strong intermolecular bonds would be difficult to damage or decompose the soil (Sitompul and Zubaidah, 2017).

\subsection{Comparison of Bioplastic Products Characteristics with Indonesian National Standard (INS) Bioplastics.}

The bioplastic product had characteristic parameters that should be considered based on the Indonesian National Standard (INS). Table 2 showed the comparison of the characteristics of the bioplastics products with INS bioplastics. Based on the results of bioplastics, it could be concluded that only two characteristics were close to the Indonesian National Standards, namely density and mass of degradation for the addition of $40 \%$ concentration of sorbitol with density value about 0.941 $(\mathrm{g} / \mathrm{mL})$ and degradation mass about $32.05 \%$.

\section{CONCLUSIONS}

Based on the results of the study, it concluded that the type and concentration of plasticizers namely sorbitol and glycerol gave different effects on the characteristics of the bioplastics product. The best result of glycerol addition for the bioplastic characteristics was in $40 \%$ concentration for highest wavenumber of $\mathrm{OH}$ groups about $3313.80 \mathrm{~cm}^{-1}$, with the smoother and fewer pores, density about $0.836 \mathrm{~g} / \mathrm{mL}$, tensile strength about $0.818 \mathrm{MPa}$, water absorption value around $22.23 \%$, and degradation plastic mass about $39.7 \%$, and the $20 \%$ concentration for percent elongation at $2.63 \%$ and young's modulus about $0.662 \mathrm{MPa}$.

The addition of sorbitol also affected the bioplastic characteristics, where the best result was found in $40 \%$ concentration with the highest wavenumber of $\mathrm{OH}$ groups about 3285.91 $\mathrm{cm}^{-1}$, with the smoother and fewer pores, bioplastic density of about $0.94 \mathrm{~g} / \mathrm{mL}$, percent elongation at $3.94 \%$, young's Modulus about $0.726 \mathrm{MPa}$, and degradation mass about $32.05 \%$, and the $20 \%$ concentration for tensile strength value about 286.1 $\mathrm{KPa}$ and water absorption at 37.27. The best result where the density and mass of degradation were close to the standard which was found in the $40 \%$ sorbitol sample with density around $0.94 \mathrm{~g} / \mathrm{mL}$ and degradation mass around $32.05 \%$.

\section{ACKNOWLEDGEMENT}

This research was funded by Sriwijaya University. Therefore, we appreciate for the help and support in this work. We also thank the reviewer colleagues who have given suggestions in this manuscript.

\section{REFERENCES}

Andahera, C., I. Sholikhah, D. A. Islamiati, and M. D. Pusfitasari (2019). Effect of Addition of Types and Concentrations of Plasticizers on the Quality of Cellulose-Based Bioplastics from Oil Palm Empty Fruit Bunches. Indonesian Journal of Pure and Applied Chemistry, 2(2); 46-54

Andaka, G. (2016). Synthesis of Furfural From Kapok Fruit Peel With Hydrochloric Acid Catalyst. Jurnal Teknologi Technoscientia, 9(1); 32-38

Ardiansyah, R. (2011). Utilization of Root form Garut for the manufacture of biodegradable plastic. Master's thesis

Azizaturrohmah, A. (2019). Comparison of Glycerol and Sorbitol Plasticizers in Sago Starch Bioplastics (Metroxylon sp.) with the Addition of Sweet Orange Peel Oil (Citrus Sinensis L.) as Antioxidants. Ph.D. thesis, UIN Sunan Ampel Surabaya

Chaiarrekij, S., A. Apirakchaiskul, K. Suvarnakich, and S. Kiatkamjornwong (2012). Kapok I : Characteristics of Kapok Fiber as a Potential Pulp Source for Papermaking. BioResources, 7(1); 0475-0488

da Rosa Zavareze, E., V. Z. Pinto, B. Klein, S. L. M. El Halal, M. C. Elias, C. Prentice-Hernández, and A. R. G. Dias (2012). Development of Oxidised and Heat-moisture Treated Potato Starch Film. Food Chemistry, 132(1); 344350

Darni, Y., H. Utami, et al. (2017). Application of Sorghum Stem Filler in Bioplastic Synthesis with PEG-400 Plasticizer and Palmitic Acid. Jurnal UAD Chemica, 4(2); 39-45

Febrila, P. Z. (2019). Catalytic Study of Kapok Randu (Ceiba Pentandra) Leaf Extract for Treating Heartburn. Journal of Chemical, 1(1); 1-25

Haryono, H., S. Solihudin, E. Ernawati, and F. Arifiadi (2019). Biodiesel from Kapok Seed Oil (Ceiba Pentandra) Ozonized Through Ultrasonic Assisted Process. Jurnal Teknik Kimia, 13(2); 61-66

Intan, D. H. and A. Wan (2011). Tensile and Water Absorbtion of Biodegradable Composites Derived from Cassava Skin/Polyvinil Alcohol with Glycerol as Plsticizer. Sains Malaysia, 40(1); 713-718

Isnaini, S. U. N. (2019). Pengaruh Penambahan Sorbitol Terhadap Karakteristik Plastik Biodegradable Berbahan Selulosa Dari Cangkang Buah Nipah (Nypa fruticans). Ph.D. thesis, UIN Walisongo

Jambeck, J. R., R. Geyer, C. Wilcox, T. R. Siegler, M. Perryman, A. Andrady, R. Narayan, and K. L. Law (2015). Plastic Waste Inputs from Land Into The Ocean. Science, 347(6223); 768-771

Jannah, M. (2017). Determination of the Optimum Concentration of Rice Husk Cellulose in Making Bioplastic Films. Ph.D. thesis, Universitas Islam Negeri Alauddin Makassar

Kathomdani, P. D. S. (2018). Kraft Pulp From Kapok And Pineapple Leaf Fiber As Raw Material For Special Paper. Jurnal Dinamika Penelitian Industri, 29(2); 108-119

Kinney, T., C. Masiello, B. Dugan, W. Hockaday, M. Dean, K. Zygourakis, and R. Barnes (2012). Hydrologic Properties 
of Biochars Produced at Different Temperatures. Biomass and Bioenergy, 41(30); 34-43

Kumar, A., Y. S. Negi, V. Choudhary, and N. K. Bhardwaj (2014). Characterization of Cellulose Nanocrystals Produced by Acid-Hydrolysis from Sugarcane Bagasse as Agro-Waste. Journal of Materials Physics and Chemistry, 2(1); 1-8

Lestari, P. A. (2015). Utilization of Kapok Seed Meal (Ceiba Pentandra) as a Mixture of Husk briquettes. Journal of Chemistry, 4(1); 1-5

Lopes, J. d. O., R. A. Garcia, and N. D. d. Souza (2018). InfraRed Spectroscopy of the Surface of Thermally-Modified Teak Juvenile Wood. Maderas. Ciencia y tecnología, 20(4); 737-746

Maghfur, M. I. (2015). Synthesis and Characterization of Edible Film from Shrimp Skin Waste, Aloe Vera and Sorbitol as Alternative Food Packaging. Master's thesis

Maneking, E., H. F. Sangian, and S. H. J. Tongkukut (2020). Production and Characterization of Bioplastics Based on Biomass with Glycerol Plasticizer. Jurnal MIPA, 9(1); 2327

Mardiyati, M., R. R. Rizkiansyah, S. Steven, A. Basuki, and R. Suratman (2018). Kapok Fiber as Raw Material for Making Microcrystalline Cellulose. Jurnal Sains Materi Indonesia, 17(4); 172-177

Nahir, N. (2017). Effect of Addition of Chitosan on Bioplastic Characteristics of Tamarind Seed Starch (Tamarindus indica L). Ph.D. thesis, Universitas Islam Negeri Alauddin Makassar

Nahwi, N. F. (2016). Analysis of the Effect of Addition of Glycerol Plasticizer on Edible Film Characteristics of Starch of Banana Peel, Corn Cobs and Water Hyacinth Cobs. Ph.D. thesis, Universitas Islam Negeri Maulana Malik Ibrahim

Ningsih, S. H. (2015). Effect of Glycerol Plasticizer on Edible Film Characteristics of Mixed Whey and Agar. Ph.D. thesis

Nurhayati, N. and R. Kusumawati (2014). Sintesis Selulosa Asetat dari Limbah Pengolahan Agar. Synthesis of Cellulose Acetate from Agar Processing Waste, 9(2); 97-107

of East Java Province, B. (2018). Kapok Production in East Java in 2006-2015 (Ton)

Pavia, D. L., G. M. Lampman, G. S. Kriz, and J. A. Vyvyan (2001). Introduction to spectroscopy. Cengage Learning

Pratiwi, R., D. Rahayu, and M. I. Barliana (2016). Utilization of Cellulose from Rice Straw Waste (Oryza sativa) as Bioplastic Material. Indonesian Journal of Pharmaceutical Science and Technology, 3(3); 83-91

Purnawati, R., F. Febrianto, N. J. Wistara, S. Nikmatin, S. Sudirman, and M. Marwanto (2018). Application of Kapok and Balsa Fibers with Alkali Treatment as Composite Reinforcing Materials. Jurnal Ilmu dan Teknologi Kayu Tropis, 16(1); 23-33

Rahmatullah, R., R. W. Putri, A. M. Rainadi, A. Permatasari, and M. Y. Pratama (2020). Effect of Reaction Time and Glycerol Additives on the Synthesis of Cellulose Acetate as a Bioplastic Base Material from Kapok Fiber. Jurnal Dinamika Penelitian Industri, 31(1); 34-41
Ratnawati, S. (2020). Processing of Plastic Waste Into Alternative Fuels in The Form of Grounded (Pertalasic) Therough Pirolysis Process in Science Laboratory of MTsN 3 West Aceh. Indonesian Journal of Chemical Science and Technology (IJCST), 3(1); 8-16

Rifaldi, A., I. Hs, and B. Bahruddin (2017). Sago Starch Based Bioplastic Properties and Morphology with Addition of Clay Filler and Glycerol Plasticizer. Jurnal Jom Teknik, 4(1); 1-7 Riza, M., S. Darmadi, and N. Abidah (2013). Synthesis of Biodegradable Plastics from Sago Starch with Glycerol and Sorbitol as Plasticizers. In Seminar nasional kimia dan pendidikan kimia $V$

Rohmawati, B., F. A. N. Sya'idah, D. Alighiri, W. T. Eden, et al. (2018). Synthesis of Bioplastic-based Renewable Cellulose Acetate from Teak Wood (Tectona grandis) Biowaste Using Glycerol- Chitosan Plasticizer. Oriental Journal of Chemistry, 34(4); 1810

Salinas-Jasso, T. A., M. L. Flores-López, J. Vieira, A. CharlesRodríguez, A. Robledo-Olivo, O. B. Á. PéreZ, R. R. Molina, and M. A. De León-Zapata (2021). Biopolymer Extraction and Its Use in Edible Packaging. Handbook of Research on Bioenergy and Biomaterials: Consolidated and Green Processes; 391

Sanyang, M. L., S. M. Sapuan, M. Jawaid, M. R. Ishak, and J. Sahari (2015). Effect of Plasticizer Type and Consentration on Tansile, Themal and Barrier Properties of Biodegradable Films Based on Sugar Palm (Arenga pinnata) Starch. Polymers, 7(6); 1106-1124

Setiawan, H., R. Faizal, and A. Amrullah (2015). Determination of Optimum Conditions for Modifying the Concentration of Plasticizer Sorbitol PVA in the Synthesis of Biodegradable Plastics Based on Sorghum Starch and Chitosan Shrimp Shell Waste. Jurnal Sains dan Teknologi, 13(1); $29-38$

Siregar, B. A. S. (2009). Characterization and Biodegradation of Poly Alloy (Styrofoam-Starch) with Poly Lactic Acid as a Biocompatible Material. Master's thesis

Sitompul, A. J. W. S. and E. Zubaidah (2017). Effect of Type and Concentration of Plasticizer on Physical Properties of Kolang Kaling (Arenga pinnata) Edible Film. Jurnal Pangan dan Agroindustri, 5(1); 17-18

Tamiogy, W. R., A. Kardisa, H. Hisbullah, and S. Aprilia (2019). Utilization of Cellulose from Betel Peel Waste as a Filler in the Making of Bioplastics. Jurnal Rekayasa Kimia and Lingkungan, 14(1); 63-71

Unsa, L. K. and G. A. Paramastri (2018). Kajian jenis plasticizer campuran gliserol dan sorbitol terhadap sintesis dan karakterisasi edible film pati bonggol pisang sebagai pengemas buah apel. Jurnal Kompetensi Teknik, 10(1); 35-47

Wahyuni, S., P. Ningsih, and R. Ratman (2017). Utilization of Kapok Seed Activated Charcoal (Ceiba Pentandra 1.) as an Adsorbent for Lead (Pb). Jurnal Akademika Kimia, 5(4); 191-196 